Zwischenraum zu hinterlassen, die Zellen ausfüllen, während bei den extrahierten Samen der Umriß der Körner unregelmäßig und zerrissen ist, und große Hohlräume sich zwischen den einzelnen Körnern befinden. Die Bestimmung des ätherischen Öles gibt nur dann brauchbare Werte, wenn bedeutende Mengen gefälschter Körner beigemiscbt sind.

J. Großfeld.

H. Imbert und A. Juillet: Die Mehle von schwarzem Senf. (Annal. Falsific. $1913,6,460-462$.

\title{
Gärungserscheinungen.
}

H. Euler: Über die Rolle des Glykogens bei der Gärung durch lebende Hefe. (Zeitsehr. physiol. Chem. 1914, 89, 337-344.) - Die Untersuchungen des Verf.'s bezweckten, den Zusammenhang zwischen Glykogenbildung und Kohlensäureentwickelung bezw. Zuckerverlust in den die lebende Hefe umgebenden Lösungen festzustellen. Es zeigte sich, daß, obwohl Glykogen verbraucht wird, die prozentische Reduktionsänderung der Lösung kleiner ist als die Drehungsänderung. Von $1 \mathrm{~g}$ Hefe wurden durchschnittlich $0,08 \mathrm{~g}$ Glykogen verbraucht, also etwa $0,09 \mathrm{~g}$ Glykose aus der Lösung entfernt. Dies entspricht einem Mebrverbrauch an Glykose von rund $1 \%$. Der Umstand, daß die Differenz $A-\mathrm{C}(\Delta=$ Drebungsrückgang, $\mathrm{C}=$ Menge der entwickelten Kohlensäure in $\%$ ) durchaus nicht mit der Menge der angewandten Hefe proportional ist, vielmehr beinahe davon unabhängig ist, zeigt, daß keineswegs diese ganze Differenz auf Rechnung der Glykogenbildung zu setzen ist. Falls Glykogen als Zwischenprodukt bei der Gärung auftritt, ist es jedenfalls nicht dasjenige, welches die Differenz $A-\mathrm{C}$ verursacht. Etwa die gleichen Verhältnisse, nur mit geringen quantitativen Abweichungen treten auf, wenn statt GJykose Fruktose und Mannose verwendet wird. Dieser Befund zeigt, daß, wenn die Vergärung über das Glykogen als Zwischenprodukt verläuft, eine sehr schnelle Isomerisation der Hexosen eintritt. Einstweilen kann aus dem zeitlichen Verlauf der Glykogenbildung noch kein sicherer Schluß auf die Rolle des Glykogens als Zwischenprodukt der Gärung gezogen werden.

G. Sonntag.

H. Euler: Über die Rolle des GIykogens bei der Gärung durch lebende Hefe. II. Mitteilung. (Zeitschr. physiol. Chemie 1914, 90, 355-366.) - Zu der Mitteilung von Harden und Young (Biochem. Journ. 1913, 7, 630) über die Bildung einer rechtsdrehenden glykogenartigen Substanz in dem Extrakt von Trockenhefe bei der Vergärung von Fructose betont Verf., daß er sich nicht in der Weise über die Deutung der Differenz $A-\mathrm{C}$ ausgesprochen habe, wie von diesen Forschern angegeben worden ist, vielmehr die Ergebnisse seiner und seiner Mitarbeiter Arbeiten stets als empirische Feststellungen betrachtet habe, Weitere Versuche, über die Verf. berichtet, haben die früheren Ergebnisse bestätigt: die Differenz $A-\mathrm{C}$ kann nicht von der Bildung von Glykogen herrühren, da dieses beim Auftreten der Differenz nicht gebildet wird, sondern im Gegenteil verschwindet.

G. Sonntag.

S. Kullberg: Über die gleichzeitige Veränderung des Gehaltes an Glykogen, an Stickstoff und an Enzymen in der lebenden Hefe. (Zeitschr. physiol. Chem. 1914, 92, 340-359.) - Ein Zusammenhang zwischen Stickstoff und Glykogen der Hefe war früher insofern untersucht worden, als man verschieden $\mathrm{Rassen}$ in bezug auf beide Stoffe verglichen hat. Dagegen sind noch nicht bei derselben Reinkulturhefe die Veränderungen beider Stoffe gleichzeitig verfolgt worden. Dies war die Hauptaufgabe der vorliegenden Untersuchung. Dabei bat sich im allgemeinen die durch Vergleich verschiedener Hefen von Schönfeld gefundene Regel bestätigt, daß höherer Glykogengehalt niederem Stickstoffgehalt entspricht und umgekehrt. Die Untersuchung zeigte jedoch, daß man von einer inversen Proportionalität 
dieser Größen nicht reden kann. Aus dem quantitativen Vergleich geht hervor, daß wirklich große Veränderungen in der Glykogensubstanz bezw. solche der hochmolekularen Kohlenhydrate eintreten. Es hat sich bestätigt, daß in untergäriger Bierhefe zu Anfang der Gärung der Glykogengehalt erheblich sinkt. Als wesentlich neues Ergebnis muß aber festgestellt werden, daß eine solche Verminderung des Glykogens durch die Gärung bei vorbehandelter Hefe nicht eintritt, sondern daß hier im Gegenteil das Glykogen stark wächst. Bei den gleichzeitigen Invertasebestimmungen bemerkt man, daß die Minima des Invertasegehaltes mit diesen Erhöhungen des Glykogengehaltes zusammenfallen. Die Gärkraft bleibt bei dieser Vorbehandlung konstant. Bemerkenswert ist ferner folgendes: Wird die Hefe nach 20-stündiger Vorbehandlung wiederholt in neue Nährlösung übergeimpft, so steigt mit jeder Überführung der Glykogengehalt and erreicht schlieblich ein Maximum. Also tritt hier bei jeder folgenden Gärung der Hefe in 2\%-iger Saccharoselösung eine Steigerung des Glykogens ein. Worauf die auffallenden Änderungen des Glykogens in vorbehandelter Hefe beruhen, konnte vom Verf. noch nicht festgestellt werden.

Max Muiller.

F. Salkowski: Über die Bestimmung des Glykogens in der Hefe. (Zeitschr. physiol. Chem. 1914, 92, 75-88.) - Verf. hat durch Versuche festgestellt, daß das von Schönfeld, Krampf, Künzel und Euler nach dem Verfahren von Pflüger durch Kochen mit 60\%-iger Kalilauge aus Hefe erhaltene "Glykogen" aus Pflanzengummi besteht. Zum Nachweise des Hefegummis bediente sich Verf. der Ausfällung mit Fehling'scher Lösung unter Zusatz von Natronlauge, das Filtrat wurde nach Entfernung des Kupfers durch Schwefelwasserstoff mit Salzsäure hydrolysiert und der gebildete Zucker bestimmt, aus dem sich das sog. Hefeglykogen berechnen läßt. Es zeigte sich jedoch, daß dieses Verfahren nicht anwendbar ist, weil aus der Hefecellulose beim Kochen mit Kalilauge ein Kohlenhydrat in Lösung geht, das sich wie Glykogen verhält und als solches mitbestimmt wird. Durch weitere Versuche kommt Verf. zu der Ansicht, dal es ein besonderes Hefeglykogen nicht gibt, sondern daß dieser Körper nichts weiter ist als ein Umwandlungsprodukt eines Teiles der Cellulose, und zwar desjenigen, den Verf. früher nach der Eigenschaft, sich mit Jod rotbraun zu färben, Erythrocellulose genannt hat.

Max Müller.

M. Oppenheimer: Über die Bildung von Milchsäure bei der alkoholischen Gärung. (Zeitschr. physiol. Chem. 1914, 89, 45̃-62.) - Die mit Hefemazerationssaft angestellten Versuche haben gezeigt, dafo bei der zellfreien Gärung unter Ausschluß von Bakterien Milchsäure als Nebenerzeugnis der alkoholischen Gärung gebildet wird. . Die Steigerung der Milchsäurebildung bei Zuckerzusatz beweist, daß die Annahme von Zucker als Milchsäurequelle berechtigt ist, ferner zeigt die sehr erhebliche Steigerung bei Zusatz von Glycerinaldehyd und Dioxyaceton, da beiden Stoffe als Vorstufen der Milchsäure in Betracht kommen können. Die beobachtete weitaus raschere und stärkere Angreifbarkeit des Glycerinaldehyds gegenüber dem Dioxyaceton läßt vielleicht auch den Schluß zu, daß Glycerinaldehyd ebenso wie beim Zuckerahbau im tierischen Organismus auch bei der alkoholischen Gärung die direkte Vorstufe der Milchsäure ist. Der anscheinende Widerspruch, daß bei bakterienfreier Gärung mit lebender Hefe keine Milchsäure auftritt, erklärt sich vielleicht dadurch, daf beim Hefepreßsaft und -mazerationssaft die spezifischen Gärungsenzyme (Zymase) geschädigt oder geschwächt sind, dagegen die bei der Milchsäurebildung beteiligten Fermente viel widerstandsfähiger sind. Die bei der Gärung mit einer Reinkultur lebender Hefezellen entstehenden ungeschwächten Enzyme lassen eine Milchsäurebildung nicht aufkommen. Je mehr die Gärkraft lebender Hefezellen oder eines Hefesaftes geschädigt oder auch nur vorübergehend gehemmt ist, desto stärker ist die Milchsäurebildung. 
M. Oppenheimer: Über die Bildung von Glycerin bei der alkoholischen Gärung. (Zeitschr. physiol. Chem. 1914, 89, 63-77.) - Die in gleicher Weise wie in den Versuchen über Milchsäurebildung mit Hefemazerationssaft angestellten Versuche (s. d. vorstehende Referat) bestätigten die von $\mathrm{Buchner}$ und Meisenheimer beobachtete Tatsache der Glycerinbildung aus Traubenzucker im Hefensafte und ergaben, daß sowohl Dioxyaceion als auch Glycerinaldehyd starke Glycerinbildner sind. Das Dioxyaceton überwiegt dabei und ist daher als Hauptquelle des Glycerins bei der alkoholischen Gärung anzusehen. Wie bei der Milchsäurebildung wurde auch bei der Glycerinbildung eine auffallende Beziehung zwischen dieser und der Gärkraft des Hefesaftes beobachtet, sodaß auch die Glycerinbildung um so stärker ist, je schwächer die Gärkraft der angewendeten Hefe oder des Hefesaftes ist. Verf. teilt ferner Ergebnisse von Versuchen über Gärkraft und Selbstgärung des Hefemazerationssaftes mit. Bei Anwendung derselben Trockenhefe zur Darstellung des Saftes ist die Gesam tgärkraft innerhalb geringer Grenzen stets dieselbe, bei verschiedener Trockenhefe kann sie sehr verschieden sein. Die Anfangsgärung ist vollkommen unabhängig von der Gesamtgärung. Bei allen Versuchen mit Hefemazerationssaft ist es daher unbedingt notwendig, vollständige Gärkraftbestimmungen in bestimmten $A b$ ständen bis zur beendeten Gärung durchzuführen; die Angabe der Gesamtgärkraft würde nicht genügen. Die Angabe v. Lebedew's und anderer Beobachter, daß Hefemazerationssaft keine Selbstgärung besitze, da er glykogenfrei sei, muß eingeschränkt werden. Von 13 Hefesäften zeigten 2 keine Selbstgärung, 3 Spuren einer Kohlensäureentwickelung, alle anderen deutliche, 2 sogar starke Selbstgärung.

\section{G. Sonntag.}

S. Kostytschew : Über Alkoholgärung. VI. Das Wesen der Reduktion von Acetaldehyd durch lebende Hefe. (Zeitschr. physiol. Chem. 1914, 89, 367-372.) - Verf. hat früher die Vermutung ausgesprochen, daß bei der Bildung von Äthylalkohol aus Acetaldehyd, die von lebender und von getöteter Hefe bewirkt wird, Reduktion von Acetaldehyd durch den bei der Gärung entstehenden aktiven Wasserstoff stattfindet. Die weiteren Untersuchungen haben jedoch ergeben, daß bei der Verarbeitung von Acetaldehyd durch lebende Hefe neben Äthylalkohol immer Essigsäure in äquimolekularer Menge entsteht, gemäß der Cannizzaro'schen Reaktion: $2 \mathrm{CH}_{3} \mathrm{COH}+\mathrm{H}_{2} \mathrm{O}=\mathrm{CH}_{3} \mathrm{CH}_{2} \mathrm{OH}+\mathrm{CH}_{3} \mathrm{COOH}$.

Q. Sonntag.

S. Kostytschew: Über Alkoholgärung. VII. Die Verarbeitung von A cetaldehyd durch Hefe bei verschiedenen Verhältnissen. (Zeitschr. physiol. Chem. 1914, 92, 402-415.) - In Fortsetzung seiner früheren Versuche, bei denen Verf. zeigen konnte, daß bei der Verarbeitung von Acetaldehyd durch lebende Preßhefe äquimolekulare Mengen Äthylalkohol und Essigsäure entstehen, hat Verf. Untersuchuugen angestellt, aus denen hervorgeht, daß Hefefermente imstande sind, den Acetaldehyd nicht nach $\mathrm{Cannizzaro,} \mathrm{sondern} \mathrm{auf} \mathrm{eine} \mathrm{andere,} \mathrm{einstweilen}$ nicht näher zu bestimmende Weise, zu verarbeiten. Diese Ergebnisse veranlaßten den Verf. zu versuchen, das Wesen der Aldehydverarbeitung durch Preßhefe zu verändern, was auch leicht gelang. In Gegenwart von verdünnter Ameisensäure (bis $\mathrm{zu} 0,08 \%$ ) wird der größte Teil des Acetaldehyds ohne entsprechende Bildung von Essigsäure reduziert. Der Mechanismus der Ameisensäurewirkung ist nicht recht verständlich; einerseits könnte die saure Reaktion von Bedeutung sein, andererseits ist die Möglichkeit einer direkten Reduktionswirkung nicht ausgeschlossen. Da aber die Ameisensäure auch bei Abwesenheit von Acetaldehyd durch Hefe verarbeitet wird, so kann die Frage nach der reduzierenden Wirkung der Ameisensäure noch nicht endgültig gelöst werden. Nicht ohne Bedeutung scheint der Umstand zu sein, daß in Gegenwart von Zinkchlorid neben Acetaldehyd auch eine geringe Menge Ameisensäure gebildet wird. 